Est i mat i on of organ doses and ef fect i ve doses i $n$ i mage - gui ded respi $r$ at i on- gat ed r adi ot her apy.

\begin{tabular}{|c|c|}
\hline 著者 & 中尾 稔 \\
\hline 著者別表示 & Nakao M nor u \\
\hline $\begin{array}{l}\text { j our nal or } \\
\text { publ i cat } i \text { on } t i t l e\end{array}$ & 博士論文本文Ful I \\
\hline 学位授与番号 & 13301甲第4301号 \\
\hline 学位名 & 博士 (保健学) \\
\hline 学位授与年月日 & $2015-09-28$ \\
\hline URL & ht t p: //hdl . handl e. net /2297/44525 \\
\hline
\end{tabular}




\title{
ESTIMATION OF ORGAN DOSES AND EFFECTIVE DOSES IN IMAGE-GUIDED RESPIRATION-GATED RADIOTHERAPY
}

\author{
Minoru Nakao ${ }^{1,2, *}$, Satoshi Obara ${ }^{1,3}$, Kuniaki Nabatame1, Keiichi Akahane', Shigeru Sanada² and \\ Toshiyuki Shirai ${ }^{1}$ \\ ${ }^{1}$ National Institute of Radiological Sciences, 4-9-1 Anagawa, Inage-ku, Chiba 263-8555, Japan \\ ${ }^{2}$ Kanazawa University, 5-11-80, Kodatsuno, Kanazawa, Ishikawa 920-0942, Japan \\ ${ }^{3}$ University of Tsukuba, 1-1-1 Tennodai, Tsukuba, Ibaraki 305-8577, Japan \\ *Corresponding author: mnrnakao@nirs.go.jp
}

Received 2 November 2014; revised 4 February 2015; accepted 5 February 2015

\begin{abstract}
Dose conformity in thoracic and abdominal ion-beam radiotherapy is degraded by respiratory motion. To improve conformity, an image-guided respiration-gated system can be used in the treatment room. The purpose of this study was to estimate the organ doses and effective doses to patients from an image-guided respiration-gated system. Glass dosemeters were inserted into an adult anthropomorphic phantom and were attached to the surface on the phantom. The phantom was placed on the treatment couch, and the imaging dose from fluoroscopy was evaluated. In addition to the organ doses, the effective doses were also estimated according to the ICRP Publication 103. The irradiation time is over 3-5 min per beam angle. When image acquisition conditions were assumed for thoracic treatment, the effective doses and maximal skin doses were $0.48-0.79 \mathrm{mSv}$ and 5.9-9.9 mGy, respectively. The estimated doses can be the base data for considering radiological protection in the radiotherapy.
\end{abstract}

\section{INTRODUCTION}

Active beam scanning radiotherapy has recently been introduced at several particle therapy centres ${ }^{(1-3)}$. This method can deliver doses to complex tumour volumes with higher conformity than the passive beam delivery method. However, dose distribution in active beam scanning is sensitive to changes in target position and, in lung tissue, to the range variation caused by density variation with respiration.

Variation in target position and range variation can cause the degradation of dose conformity. To improve the precision of target localisation, a number of treatment centres use a respiratory-gated strategy and fourdimensional computed tomography (4DCT)-based treatment planning for thoracic and abdominal treatments. An external marker is generally used for respiratory monitoring. Indirect respiratory monitoring can in the worst case result in inconsistency between the external respiratory signal and internal organ movement ${ }^{(4)}$. To monitor internal organ movement directly, in-room fluoroscopic marker-tracking systems have been utilised ${ }^{(5,6)}$. Since the implantation of metallic markers carries a risk of pneumothorax, some groups have introduced real-time tumour tracking systems that do not use these markers ${ }^{(7,8)}$. Markerless tracking systems require higher contrast resolution than marker-tracking systems. One method of attaining high contrast images is to increase the $\mathrm{X}$-ray tube current and exposure time, but this is of course accompanied by increasing dose. Some particle therapy institutes have used 4DCT-based treatment planning to improve target coverage ${ }^{(9,10)}$. The imaging dose of
4DCT is four to six times that of helical computed tomography $(\mathrm{CT})^{(11,12)}$. Patients with thoracic or abdominal tumours receive substantial benefit from image guidance, but at the price of increased radiation dose. Because the total imaging dose is the accumulation of each imaging dose from image guidance, estimation of each imaging dose would be helpful to optimise the imaging dose and to inform clinicians about the total imaging dose for a specific treatment scenario in image-guided radiotherapy.

A new treatment facility for carbon-ion therapy was constructed at the authors' institute in 2011, and over 700 cancer patients were treated with nonrespiratory-gated irradiation by the end of July $2014^{(3)}$. A markerless tracking system and 4DCTbased treatment planning have been introduced for active beam scanning in the thoracic and abdominal regions. The total imaging dose is the sum of that from CT planning (4DCT), that from patient setup (orthogonal X-ray flat panel detector images), and that from the markerless tracking system (fluoroscopy). For image-guided particle radiotherapy, the imaging doses from 4DCT and fluoroscopy account for a large proportion of the overall imaging $\operatorname{dose}^{(13)}$. Although Matsuzaki et al. showed the organ and effective doses from $4 \mathrm{DCT}^{(12)}$, the authors are unaware of any reported estimation of the dose from fluoroscopic tumour tracking systems. Understanding the additional organ dose due to ionising radiation from image guidance methods is particularly important when the planned treatment dose to critical organs is already close to the tolerance limit. 


\section{NAKAO ETAL.}

There were two purposes to this study: the first was to estimate the imaging doses from fluoroscopy and the second was to compare the effective doses from fluoroscopy to those from other imaging modalities. These results would be helpful to optimise dose and to estimate overall imaging dose in image-guided radiotherapy.

\section{MATERIALS AND METHODS}

\section{Fluoroscopic system}

The fluoroscopic system used in this study was designed to provide respiratory gating for radiotherapy. The system consists of a pair of indirect dynamic flat panel detectors (DFPDs) (PaxScan 3030+, Varian Medical Systems, Palo Alto, CA, USA) installed on the right and left side of vertical irradiation port $\left(0^{\circ}\right)$ at 35 and $325^{\circ}$, and X-ray tubes (UD150B-40 and 0.4/0.7JG326D-265, Shimadzu Co., Kyoto, Japan) installed under radiolucent floor panels. The imaging area is $296 \times 296 \mathrm{~mm}$ (actual image size at room isocentre $209 \times 209 \mathrm{~mm}$ ). Small collimators are positioned in front of the X-ray tubes, and $0.9 \mathrm{~mm}$ aluminium and $0.01 \mathrm{~mm}$ copper filters are employed to remove lower energy photons. An antiscatter grid is not used. The image acquisition frame rate is less than 30 frames per second (fps). The effective energy and the quality index for $60,80,100$ and $120 \mathrm{kV}$ were measured in the treatment room. Quality index was defined as the effective energy divided by the maximal energy of X-ray beam. The measurement procedure was as follows: $12 \mathrm{cc}$ ionisation chamber was set at isocentre in the treatment room. The half-value layer of aluminium was obtained by increasing the thickness of high purity aluminium plates in the front of X-ray tube. The mass attenuation coefficients of aluminium were obtained by the measured half-value layers. Based on the mass attenuation coefficients, the X-ray effective energies were estimated by using the data table of the National Institute of Standards and Technology ${ }^{(14)}$.

\section{Phantom}

An adult anthropomorphic phantom (THRA-1; Kyoto Kagaku Co., Kyoto, Japan) was used for the dose measurements. The phantom models a human body with a height of $164 \mathrm{~cm}$ and a weight of $54 \mathrm{~kg}$ and is composed of materials equivalent to soft tissue (mass density: $\left.1.01 \mathrm{~g} \mathrm{~cm}^{-3}\right)$, lung $\left(0.3 \mathrm{~g} \mathrm{~cm}^{-3}\right)$ and bone $\left(1.24 \mathrm{~g} \mathrm{~cm}^{-3}\right)$. The phantom was attached two breast parts and testis part, and effective doses of reference male and reference female were evaluated. This phantom consists of 35 slices of $2.5 \mathrm{~cm}$ thickness and contains two types of 179 cylindrical 2-mm and 5 -mm holes in which glass dosemeters can be inserted to each organ position. Bone surface doses were estimated at the same position as bone marrow doses.
Remainder, which is defined in the International Commission on Radiological Protection Publication $103^{(15)}$, consists of oral mucosa, extrathoracic tissue, thymus, heart, kidney, pancreas, spleen, adrenal, small intestine and uterus. The total skin surface area of the phantom is $\sim 1.6 \mathrm{~m}^{2}$.

\section{Dosimeter}

The glass dosemeter system, Dose Ace (Asahi Techno Glass Co., Haibara, Japan) consists of a silver-activated phosphate glass dosemeter (GD-352M) and a readout unit (FDG-1000). The shape of the glass dosemeter is cylindrical, $1.5 \mathrm{~mm}$ in diameter and 12 $\mathrm{mm}$ in length. The glass dosemeter has an effective atomic number of $12.04^{(16)}$. The response of the glass dosemeter depends on X-ray energy. Energy dependence is remarkably high at lower soft X-ray energy regions. Energy dependence can be reduced by inserting the glass dosemeter into a $\mathrm{Sn}$ filter measuring 4.3 $\mathrm{mm}$ in diameter and $14.5 \mathrm{~mm}$ length. Glass dosemeters were inserted into the holder, which contained Sn filter inside, then inserted into 5-mm holes in the adult anthropomorphic phantom. Other glass dosemeters were directly inserted into 2-mm holes. The authors obtained two types of calibration factor, with and without $\mathrm{Sn}$ filters. The calibration factors were determined by comparative calibration with either a 0.6 or 12 cc ionisation chamber in a water-equivalent slab phantom (Figure 1). A 4-mm-thick aluminium plate was placed in front of the X-ray tube (YXLON International X-ray $\mathrm{GmbH}$, Hamburg, Germany) to equalise the effective energy and the quality index between calibration and measurement in the treatment room. The ionisation chambers were calibrated with a traceable ionisation chamber to the National Standard. The calibration factors were obtained for the following five conditions: with Sn filter on the surface of the phantom; with Sn filter in the phantom; without $\mathrm{Sn}$ filter in the phantom; with Sn filter outside the beam field and without $\mathrm{Sn}$ filter outside the beam field.

\section{Data acquisition}

The adult anthropomorphic phantom was placed on the treatment couch in the supine position. The centre of the phantom was matched to the isocentre in the treatment room (Figure 2a). Exposure conditions were tube voltage of $80 \mathrm{kV}$, tube current of $50 \mathrm{~mA}$, exposure time $4 \mathrm{~ms}$ per pulse and $15 \mathrm{fps}$. The dose measurements were carried out with each tube aimed at the thoracic and abdominal regions (Figure 2b).

Phantom position was calibrated using laser guides in the treatment room. To expose dosemeters to sufficient dose outside the beam field, the phantom was exposed to the X-ray beam for $30 \mathrm{~min}$ in each direction. The readout values of the glass dosemeters inside and outside the beam field were converted to 

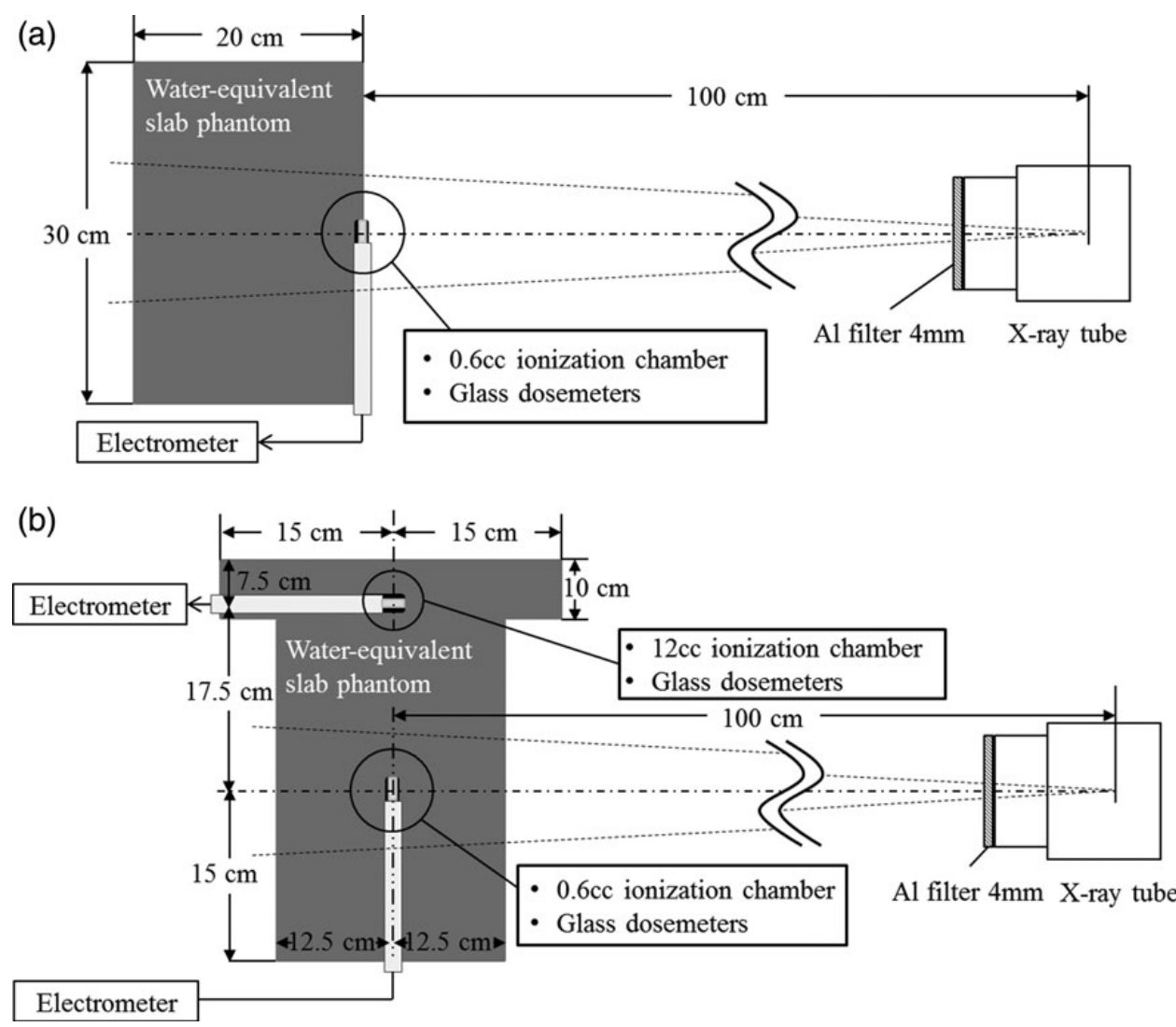

Figure 1. Arrangement for calibration of glass dosemeters. (a) Arrangement for the calibration factor on surface of phantom. (b) Arrangement for the calibration factors in phantom and outside beam field.

the absorbed doses for air with the respective calibration factors. The readout values of the dosemeters on the surface of the phantom were converted with the surface calibration factor, and the skin doses were estimated based on the absorbed doses measured at six positions (Figure $2 \mathrm{c}$ and $\mathrm{d}$ ).

\section{Organ dose calculation methods}

The absorbed doses to an organ $d_{\text {organ }}$ were calculated using the following equation:

$$
d_{\text {organ }}=d_{\text {air, dry }} \times \frac{\left(\mu_{\mathrm{en}} / \rho\right)_{\text {organ }}}{\left(\mu_{\mathrm{en}} / \rho\right)_{\mathrm{air}, \mathrm{dry}}},
$$

where $d_{\text {air,dry }}$ is the absorbed dose in dry air and $\left[\left(\mu_{\mathrm{en}} / \rho\right)_{\text {organ }} /\left(\mu_{\mathrm{en}} / \rho\right)_{\text {air, dry }}\right]$ is the ratio of the mass energy absorption coefficient of an organ to that of dry air ${ }^{(17)}$. Most organ doses were the average of doses delivered to all dosemeters for that organ. Due to the difficulty in selecting appropriate measurement points, however, organ doses for the bone marrow, bone surface, colon and skin were estimated by an organspecific method. The bone marrow dose $\left(d_{\text {bone marrow }}\right)$ and bone surface dose ( $\left.d_{\text {bone surface }}\right)$ were estimated using the dosemeters inserted in bone. For bone marrow and bone surface, the conversions for absorbed doses to organ doses were based on the following equations $^{(18)}$ :

$$
\begin{aligned}
d_{\text {bone marrow }}= & \sum_{i} d_{\mathrm{abs}, i} A_{i}, \\
d_{\text {bone surface }}= & \left\{\sum_{i} d_{\mathrm{abs}, i} M_{i}\right\}\left[\frac{1}{\left(\mu_{\mathrm{en}} / \rho\right)_{\text {soft tissue }}}\right. \\
& \left.\times \frac{\left\{\left(\mu_{\mathrm{en}} / \rho\right)_{\text {soft tissue }}+\left(\mu_{\mathrm{en}} / \rho\right)_{\text {corticalbone }}\right\}}{2}\right],
\end{aligned}
$$

where $d_{\mathrm{abs}, i}$ is the absorbed dose to soft tissue, which was converted by Equation (1); $A_{i}$ is the ratio of each 
(a)

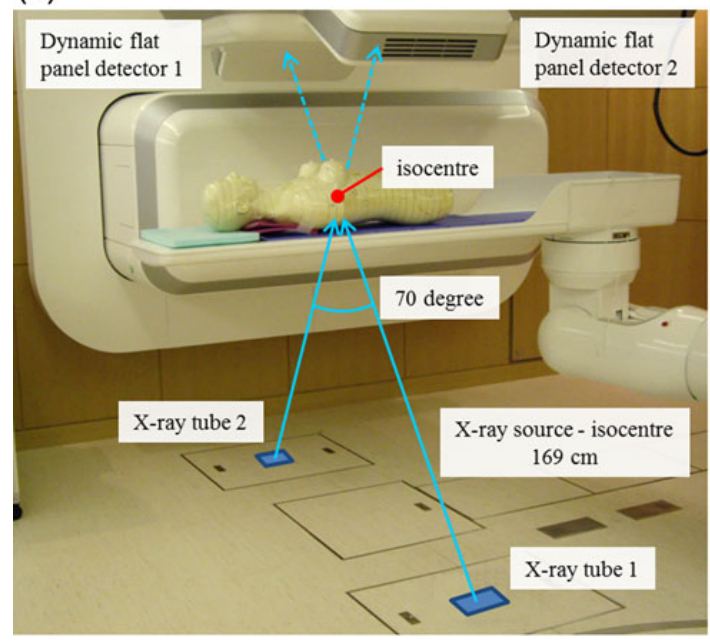

(b)

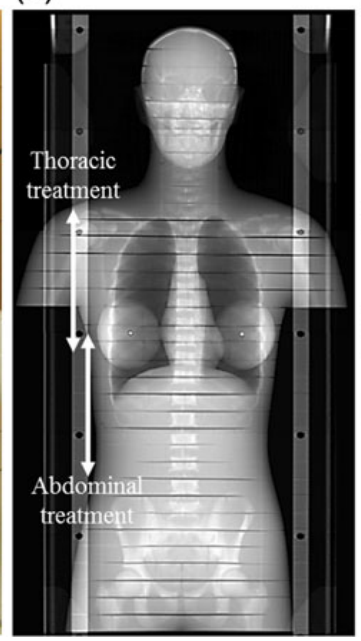

(c)

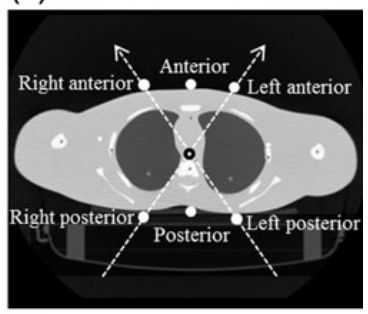

(d)

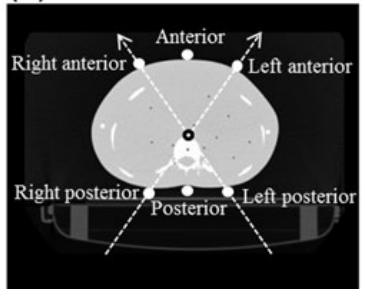

Figure 2. (a) X-ray fluoroscopic system consisting of a pair of DFPDs and two X-ray tubes. An anthropomorphic phantom was placed on the treatment couch for dose measurement. (b) Exposure areas were set for the thoracic or abdominal regions. (c) Measurement points of skin dose for the thoracic treatment. (d) Measurement points of skin dose for the abdominal treatment.

fraction to total red bone marrow weight; $M_{i}$ is the ratio of each fraction to total mineralised bone weight and $\left(\mu_{\mathrm{en}} / \rho\right)_{\text {cortical tissue }}$ and $\left(\mu_{\mathrm{en}} / \rho\right)_{\text {soft tissue }}$ are the mass energy absorption coefficients for cortical bone and soft tissue, respectively. $A_{i}$ and $M_{i}$ can be obtained from ICRP Publication $70^{(19)}$. The absolute colon dose $\left(d_{\text {colon }}\right)$ was estimated by the following equations $^{(20)}$ :

$$
d_{\text {colon }}=0.57 d_{\mathrm{ULI}}+0.43 d_{\mathrm{LLI}}
$$

where $d_{\mathrm{ULI}}$ and $d_{\mathrm{LLI}}$ are the absorbed doses of upper large intestine and lower large intestine, respectively.

The absorbed skin dose $\left(d_{\text {skin }}\right)$ was estimated using the following equations:

$$
\begin{aligned}
d_{\text {skin }}= & \frac{\left(d_{\text {beam-entrance skin }}+d_{\text {beam-exit skin }}\right)}{2} \\
& \times \frac{\left(A_{\text {beam-entrance skin }}+A_{\text {beam-exit skin }}\right)}{A_{\text {total skin }}},
\end{aligned}
$$

where $\left(d_{\text {beam-entrance skin }}\right)$ and $\left(A_{\text {beam-entrance skin }}\right)$ are the absorbed dose and area at the surface of X-ray beam entrance, respectively. ( $d_{\text {beam-exit }}$ skin $)$ and $\left(A_{\text {beam-exit skin }}\right)$ are the absorbed dose and area at the exit of the beam through the phantom, respectively. ( $\left.A_{\text {total skin }}\right)$ is the total skin surface area of the phantom $^{(21)}$.

The effective dose was defined as the total of the tissue-weighted equivalent doses for all tissues and organs. The effective doses were calculated by multiplying each organ dose by the tissue weighting factors suggested by ICRP Publication $103^{(15)}$.

\section{Exposure conditions for thoracic treatment}

To estimate exposure conditions for thoracic treatment, a series of radiographs of an anthropomorphic chest phantom (Chest Phantom N-1 LUNGMAN; Kyoto Kagaku Co., Kyoto, Japan) was taken with the fluoroscopic system by changing tube currents, e.g. 10,20 and $40 \mathrm{~mA}$, while holding tube voltage, exposure time and pulse rate (image acquisition per second) constant. The DFPD images were acquired with a pixel size of $388 \mu \mathrm{m}$ and a matrix size of $768 \times 768$. The DFPD image data were imported into Image $\mathbf{J}^{(22)}$ in order to view the DFPD images.

\section{RESULTS \\ $\mathrm{X}$-ray effective energies and quality indexes of fluoroscopic system}

X-ray effective energies for $60,80,100$ and $120 \mathrm{kV}$ were obtained as $33,36,39$ and $41 \mathrm{keV}$, and quality indexes for $60,80,100$ and $120 \mathrm{kV}$ were obtained as $0.54,0.45,0.39$ and 0.34 , respectively.

\section{Calibration factors of glass dosemeters}

The coefficient of variation was defined as the standard deviation divided by the averaged values. The maximum coefficient of variation in five calibration factors was $7.1 \%$ (Table 1). When the organ doses 
ORGAN DOSES AND EFFECTIVE DOSES IN IGRT

Table 1. Calibration factors and coefficient of variation.

\begin{tabular}{|c|c|c|c|c|}
\hline Holder & Position & $\begin{array}{l}\text { Number of } \\
\text { dosemeters }\end{array}$ & $\begin{array}{l}\text { Calibration factor/ } \\
\qquad{\mathrm{mGy} \mu \mathrm{Sv}^{-1}}^{-1}\end{array}$ & $\begin{array}{c}\text { Coefficient of } \\
\text { variation } / \%\end{array}$ \\
\hline \multirow[t]{3}{*}{ With Sn filter } & On surface of phantom & 10 & $1.03 \times 10^{-3}$ & 5.9 \\
\hline & In phantom & 10 & $1.09 \times 10^{-3}$ & 4.6 \\
\hline & Outside beam field & 10 & $1.2 \times 10^{-3}$ & 3.5 \\
\hline \multirow[t]{2}{*}{ Without Sn filter } & In phantom & 20 & $2.96 \times 10^{-4}$ & 4.8 \\
\hline & Outside beam field & 20 & $3.0 \times 10^{-4}$ & 7.1 \\
\hline
\end{tabular}

Table 2. Organ and effective doses for thoracic treatment.

\begin{tabular}{|c|c|c|c|c|c|c|}
\hline \multicolumn{7}{|c|}{ Thoracic treatment } \\
\hline \multirow{3}{*}{$\begin{array}{l}\text { Projection } \\
\text { X-ray tube }\end{array}$} & \multicolumn{2}{|c|}{ RPO } & \multicolumn{2}{|c|}{ LPO } & \multicolumn{2}{|c|}{$\mathrm{RPO}+\mathrm{LPO}$} \\
\hline & \multicolumn{2}{|c|}{ X-ray tube 1} & \multicolumn{2}{|c|}{ X-ray tube 2} & \multicolumn{2}{|c|}{$\mathrm{X}$-ray tube $1+\mathrm{X}$-ray tube 2} \\
\hline & $\begin{array}{l}\text { Organ dose } \\
(\mathrm{mGy} / \mathrm{mAs})\end{array}$ & $\mathrm{SD}$ & $\begin{array}{l}\text { Organ dose } \\
(\mathrm{mGy} / \mathrm{mAs})\end{array}$ & $\mathrm{SD}$ & $\begin{array}{l}\text { Organ dose } \\
(\mathrm{mGy} / \mathrm{mAs})\end{array}$ & $\mathrm{SD}$ \\
\hline \multicolumn{7}{|l|}{ Organ } \\
\hline Brain & 0.01 & $<0.01$ & 0.01 & $<0.01$ & 0.01 & 0.01 \\
\hline Lens & $<0.01$ & $<0.01$ & $<0.01$ & $<0.01$ & $<0.01$ & $<0.01$ \\
\hline Thyroid & 0.09 & 0.01 & 0.09 & 0.02 & 0.19 & 0.03 \\
\hline Lung & 0.42 & 0.22 & 0.46 & 0.23 & 0.88 & 0.43 \\
\hline Oesophagus & 0.43 & 0.26 & 0.53 & 0.38 & 0.96 & 0.64 \\
\hline Breast & 0.03 & 0.01 & 0.03 & 0.01 & 0.05 & 0.01 \\
\hline Heart & 0.18 & 0.08 & 0.23 & 0.11 & 0.41 & 0.16 \\
\hline Liver & 0.04 & 0.02 & 0.03 & 0.01 & 0.07 & 0.04 \\
\hline Stomach & 0.02 & 0.01 & 0.03 & 0.01 & 0.05 & 0.02 \\
\hline Colon & 0.01 & $\begin{array}{c}<0.01(\mathrm{ULI}) / \\
0.01(\mathrm{LLI})\end{array}$ & 0.01 & $\begin{array}{c}0.01(\mathrm{ULI}) / \\
<0.01(\mathrm{LLI})\end{array}$ & 0.01 & $\begin{array}{l}0.01 \text { (ULI)/ } \\
0.01 \text { (LLI) }\end{array}$ \\
\hline Ovaries & $<0.01$ & $<0.01$ & $<0.01$ & $<0.01$ & $<0.01$ & $<0.01$ \\
\hline Bladder & $<0.01$ & $<0.01$ & $<0.01$ & $<0.01$ & $<0.01$ & $<0.01$ \\
\hline Testes & $<0.01$ & $<0.01$ & $<0.01$ & $<0.01$ & $<0.01$ & $<0.01$ \\
\hline Bone surface & 0.25 & & 0.23 & & 0.48 & \\
\hline Bone marrow & 0.12 & & 0.10 & & 0.22 & \\
\hline Skin & 0.04 & & 0.05 & & 0.09 & \\
\hline Remainder (male) & 0.05 & & 0.06 & & 0.11 & \\
\hline Remainder (female) & 0.05 & & 0.05 & & 0.10 & \\
\hline \multicolumn{7}{|c|}{ Effective dose (mSv/100 mAs) } \\
\hline ICRP 103 publication & 0.10 & & 0.11 & & 0.22 & \\
\hline
\end{tabular}

RPO, right posterior oblique position; LPO, left posterior oblique position; ULI, upper large intestine; LLI, lower large intestine; SD, standard deviation of readout values in an organ.

were estimated in one measurement, the measured value contained the variation listed in Table 1.

\section{Measurement of organ doses and effective doses}

The results of organ and effective dose measurement in the thoracic region are listed in Table 2. Values were normalised to $100 \mathrm{mAs}$. Standard deviations do not show measurements reproducibly, but rather the variation in dose by dosemeters set at particular points in each organ. The organ doses from both irradiation directions were $0.96 \mathrm{mGy} / 100 \mathrm{mAs}, 0.88$ $\mathrm{mGy} / 100 \mathrm{mAs}, 0.48 \mathrm{mGy} / 100 \mathrm{mAs}$ and $0.41 \mathrm{mGy} /$ $100 \mathrm{mAs}$ for oesophagus, lung, bone surface and heart. Although breasts are in the thoracic region, the organ dose was low $(0.05 \mathrm{mGy} / 100 \mathrm{mAs})$ because the $\mathrm{X}$-ray entered from the back of the phantom. High organ doses for bone surface and bone marrow were due to the direct irradiation of the thoracic vertebrae, scapulae and ribs. The effective dose for thoracic treatment was $0.22 \mathrm{mSv} / 100 \mathrm{mAs}$. 
M. NAKAO ET AL.

Table 3. Organ and effective doses for abdominal treatment.

\begin{tabular}{|c|c|c|c|c|c|c|}
\hline \multicolumn{7}{|c|}{ Abdominal treatment } \\
\hline \multirow{3}{*}{$\begin{array}{l}\text { Projection } \\
\text { X-ray tube }\end{array}$} & \multicolumn{2}{|c|}{$\mathrm{RPO}$} & \multicolumn{2}{|c|}{ LPO } & \multicolumn{2}{|c|}{$\mathrm{RPO}+\mathrm{LPO}$} \\
\hline & \multicolumn{2}{|c|}{$\mathrm{X}$-ray tube 1} & \multicolumn{2}{|c|}{$\mathrm{X}$-ray tube 2} & \multicolumn{2}{|c|}{$\mathrm{X}$-ray tube $1+\mathrm{X}$-ray tube 2} \\
\hline & $\begin{array}{l}\text { Organ dose } \\
(\mathrm{mGy} / \mathrm{mAs})\end{array}$ & SD & $\begin{array}{l}\text { Organ dose } \\
(\mathrm{mGy} / \mathrm{mAs})\end{array}$ & SD & $\begin{array}{l}\text { Organ dose } \\
(\mathrm{mGy} / \mathrm{mAs})\end{array}$ & SD \\
\hline \multicolumn{7}{|l|}{ Organ } \\
\hline Brain & $<0.01$ & $<0.01$ & $<0.01$ & $<0.01$ & $<0.01$ & 0.01 \\
\hline Lens & $<0.01$ & $<0.01$ & $<0.01$ & $<0.01$ & $<0.01$ & $<0.01$ \\
\hline Thyroid & 0.01 & $<0.01$ & 0.01 & 0.01 & 0.01 & 0.02 \\
\hline Lung & 0.16 & 0.14 & 0.16 & 0.14 & 0.32 & 0.24 \\
\hline Oesophagus & 0.28 & 0.47 & 0.31 & 0.54 & 0.59 & 0.85 \\
\hline Breast & 0.03 & 0.01 & 0.02 & 0.01 & 0.05 & 0.01 \\
\hline Heart & 0.17 & 0.08 & 0.19 & 0.10 & 0.36 & 0.10 \\
\hline Liver & 0.34 & 0.18 & 0.27 & 0.15 & 0.61 & 0.18 \\
\hline Stomach & 0.13 & 0.02 & 0.17 & 0.05 & 0.30 & 0.02 \\
\hline Colon & 0.20 & $\begin{array}{l}0.12(\mathrm{ULI}) / \\
0.22 \text { (LLI) }\end{array}$ & 0.19 & $\begin{array}{l}0.20 \text { (ULI)/ } \\
0.14 \text { (LLI) }\end{array}$ & 0.39 & $\begin{array}{l}0.13 \text { (ULI) } \\
0.23 \text { (LLI) }\end{array}$ \\
\hline Ovaries & 0.01 & $<0.01$ & 0.01 & $<0.01$ & 0.01 & $<0.01$ \\
\hline Bladder & $<0.01$ & $<0.01$ & $<0.01$ & $<0.01$ & 0.01 & $<0.01$ \\
\hline Testes & 0.01 & $<0.01$ & $<0.01$ & $<0.01$ & 0.01 & $<0.01$ \\
\hline Bone surface & 0.16 & & 0.16 & & 0.31 & \\
\hline Bone marrow & 0.09 & & 0.09 & & 0.19 & \\
\hline Skin & 0.05 & & 0.04 & & 0.08 & \\
\hline Remainder (male) & 0.16 & & 0.19 & & 0.35 & \\
\hline Remainder (female) & 0.15 & & 0.17 & & 0.32 & \\
\hline \multicolumn{7}{|l|}{ Effective dose (mSv/100 mAs) } \\
\hline ICRP 103 publication & 0.12 & & 0.13 & & 0.25 & \\
\hline
\end{tabular}

RPO, right posterior oblique position; LPO, left posterior oblique position; ULI, upper large intestine; LLI, lower large intestine; $\mathrm{SD}$, standard deviation of readout values in an organ.

The organ and effective doses in the abdominal region are listed in Table 3. Large organ doses from both irradiation directions were $0.61 \mathrm{mGy} / 100 \mathrm{mAs}$, $0.59 \mathrm{mGy} / 100 \mathrm{mAs}, 0.39 \mathrm{mGy} / 100 \mathrm{mAs}, 0.36 \mathrm{mGy} /$ $100 \mathrm{mAs}$ and $0.35 \mathrm{mGy} / 100 \mathrm{mAs}$ for liver, oesophagus, colon, heart and remainder (male), respectively. The standard deviation for oesophagus dose was higher than the mean value because the dose distribution was heterogeneous near the radiation field edge. Many of the remainder organs were abdominal organs (spleen/pancreas/adrenal gland/kidney/small intestine), and thus the remainder dose for the abdominal region was higher than that for the thoracic region. The effective dose for abdominal treatment was 0.25 $\mathrm{mSv} / 100 \mathrm{mAs}$.

Skin doses in thoracic and abdominal treatment are listed in Table 4. The skin dose at the exit of the beam through the phantom was $\sim 3 \%$ of that at the beam entrance. The maximum skin doses for thoracic and abdominal treatment were $2.74 \mathrm{mGy} / 100 \mathrm{mAs}$ and $2.58 \mathrm{mGy} / 100 \mathrm{mAs}$, respectively. The maximal dose point on the skin surface was dependent on the incident X-ray direction. The maximal dose point from the bilateral X-ray beams was located between the right posterior and the left posterior. The maximum skin dose was at the posterior point because the posterior point was directly exposed to both X-ray beams. The effective dose for abdominal treatment $(0.25 \mathrm{mSv} / 100 \mathrm{mAs})$ was slightly higher than that for thoracic treatment $(0.22 \mathrm{mSv} / 100 \mathrm{mAs})$. The difference in effective doses between right posterior oblique (RPO) and left posterior oblique (LPO) was $<10 \%$. Therefore, effective dose was little affected by rotation in the plane of the long axis.

\section{Chest phantom images}

Three images acquired under different exposure conditions are shown in Figure 3. The region in dashed circle is around the isocentre in the treatment room. Image noise generally increases with decreasing dose. The pulmonary blood vessels in the lung field could be observed at low exposure dose, whereas those 
ORGAN DOSES AND EFFECTIVE DOSES IN IGRT

Table 4. Skin dose for thoracic and abdominal treatment.

\begin{tabular}{|c|c|c|c|c|c|c|}
\hline \multirow[b]{2}{*}{$\begin{array}{l}\text { Projection } \\
\text { X-ray tube }\end{array}$} & \multicolumn{3}{|c|}{ Thoracic treatment } & \multicolumn{3}{|c|}{ Abdominal treatment } \\
\hline & $\begin{array}{c}\text { RPO } \\
\text { X-ray tube } 1\end{array}$ & $\begin{array}{c}\text { LPO } \\
\text { X-ray tube } 2\end{array}$ & $\begin{array}{c}\mathrm{RPO}+\mathrm{LPO} \\
\mathrm{X} \text {-ray tube } 1+ \\
\mathrm{X} \text {-ray tube } 2\end{array}$ & $\begin{array}{c}\text { RPO } \\
\text { X-ray tube } 1\end{array}$ & $\begin{array}{c}\text { LPO } \\
\text { X-ray tube } 2\end{array}$ & $\begin{array}{c}\mathrm{RPO}+\mathrm{LPO} \\
\mathrm{X} \text {-ray tube } 1+ \\
\text { X-ray tube } 2\end{array}$ \\
\hline \multicolumn{7}{|c|}{ Skin dose (mGy/100 mAs) } \\
\hline Anterior & 0.06 & 0.07 & 0.14 & 0.03 & 0.03 & 0.05 \\
\hline Left anterior & 0.05 & 0.05 & 0.10 & 0.02 & 0.05 & 0.07 \\
\hline Left posterior & 0.22 & 1.53 & 1.76 & 0.44 & 1.31 & 1.75 \\
\hline Posterior & 1.33 & 1.41 & 2.74 & 1.29 & 1.29 & 2.58 \\
\hline Right posterior & 1.47 & 0.25 & 1.71 & 1.56 & 0.47 & 2.03 \\
\hline Right anterior & 0.06 & 0.05 & 0.12 & 0.05 & 0.03 & 0.07 \\
\hline
\end{tabular}

RPO, right posterior oblique position; LPO, left posterior oblique position.

(a)
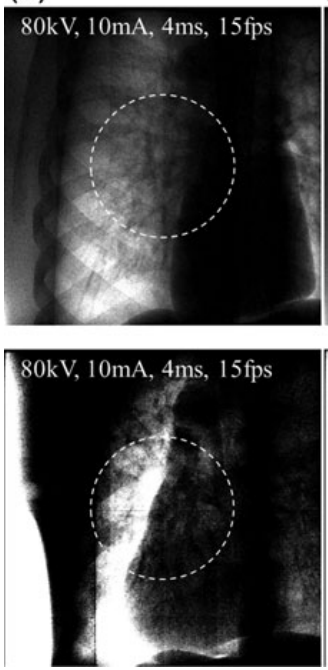

(b)

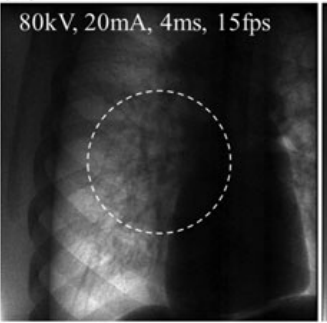

$80 \mathrm{kV}, 20 \mathrm{~mA}, 4 \mathrm{~ms}, 15 \mathrm{fps}$

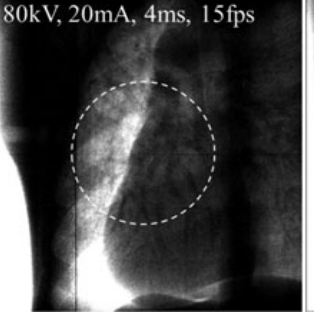

(c)

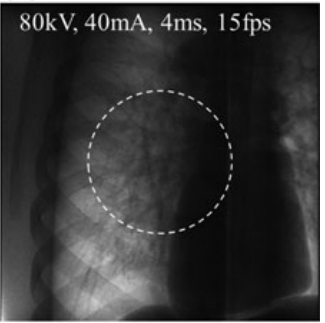

$80 \mathrm{kV}, 40 \mathrm{~mA}, 4 \mathrm{~ms}, 15 \mathrm{fps}$

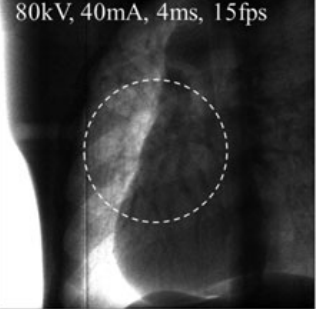

Figure 3. Images acquired with different tube currents at constant voltage, exposure time, and pulse rate. Upper and lower panels show RPO and LPO projections, respectively. The region in dashed circle is around the isocentre in treatment room. (a) $80 \mathrm{kV}, 10 \mathrm{~mA}, 4 \mathrm{~ms}$ and 15fps. (b) $80 \mathrm{kV}, 20 \mathrm{~mA}, 4 \mathrm{~ms}$ and $15 \mathrm{fps}$. (c) $80 \mathrm{kV}, 40 \mathrm{~mA}, 4 \mathrm{~ms}$ and $15 \mathrm{fps}$.

obscured by the mediastinum could not be identified at the lower exposure dose.

\section{DISCUSSION}

Thermoluminescent dosemeter has been used for measurements of organ dose and effective dose ${ }^{(11,12)}$. Glass dosemeters have better reproducibility, less fading effect than the thermoluminescent dosemeter ${ }^{(23)}$. Although glass dosemeters are not read out in real-time like silicon pin photodiode ${ }^{(18,21)}$, the exposure doses were measured in several hundred positions at one time. Because the response of the glass dosemeter depends on X-ray energy in diagnosis region, effective energy and quality index used for comparative calibration were equalised to those of $\mathrm{X}$-ray tubes in treatment room. The glass dosemeters for the calibrations were selected at random from hundreds of glass dosemeters for actual measurement in the treatment room because these hundreds of glass dosemeters have the same lot number in which the manufacture of grass dosemeter assured that the coefficient of variation was $<1 \%$ in test report. The coefficients of variation in Table 1 were given as overall 


\section{NAKAO ETAL.}

variation, which consisted of $\mathrm{X}$-ray beam intensity variation, the glass dosemeter sensitivity variation, readout error and geometrical setup error.

Organ doses were estimated by averaging the readout values of glass dosemeters because the positions of glass dosemeters had been determined in order to measure a mean organ dose. The minimal dose $0.01 \mathrm{mGy} / 100 \mathrm{mAs}$ in Tables 2-4 corresponded approximately to $0.5 \mathrm{mGy}$ of raw data. Manninen et al. $^{(24)}$ reported that glass dosemeter had linearity over $0.02 \mathrm{mGy}$. Therefore, the dose was sufficient for obtaining linearity of glass dosemeter, and the dose distributions in Tables $2-4$ have reliable accuracy. The variations between readout values of glass dosemeters in an organ were compared qualitatively with standard deviation in Tables 2 and 3. The variation among measurement points in the organ (Tables 2 and 3) was higher than the variation of calibration factor obtained by a number of measurements (Table 1). Because the variation of calibration factor was several per cent, the organ dose level could be estimated with glass dosemeters. This study quantified organ doses, effective doses and skin doses for image guidance in carbon-ion radiotherapy. The beam angle is often fixed in the treatment room in carbon-ion radiotherapy centre. Patients are treated at specific beam angles in specific body postures to keep organs at risk out of the beam. When patients are treated in such body postures, the maximal skin dose can decrease. Therefore the actual maximal skin dose in specific body postures could be safely estimated by the summed measured maximal skin dose (number of beams times the maximal skin dose per one beam).

The irradiation time is over $3-5 \mathrm{~min}$. The treatment time varies in the width of the gating window and the patient's respiratory cycle ${ }^{(25)}$. When the authors assume image acquisition conditions of 80 $\mathrm{kV}, 20 \mathrm{~mA}, 4 \mathrm{~ms}$ and $15 \mathrm{fps}$ for thoracic regions, the effective dose and maximal skin dose are $0.48-0.79$ $\mathrm{mSv}$ per beam angle $\left(=2.2 \times 10^{-3} \mathrm{mSv} \mathrm{mAs}^{-1} \times 72\right.$ $\left.\mathrm{mAs} \min ^{-1} \times 3-5 \mathrm{~min}\right)$ and $5.9-9.9 \mathrm{mGy}$ per beam angle $\left(=2.74 \times 10^{-2} \mathrm{mGy} \mathrm{mAs}^{-1} \times 72 \mathrm{mAs}\right.$ $\left.\min ^{-1} \times 3-5 \mathrm{~min}\right)$, respectively. The Marburger Ionen Therapie (MIT) and Heidelberg Ion-Beam Therapy Center (HIT) have also installed fluoroscopic systems in their treatment rooms ${ }^{(13)}$. Maximal skin doses at MIT and HIT when fluoroscopy is performed for lung cancer treatment are $8 \mathrm{mGy}$ ( 3 min anteriorposterior procedure) and $5 \mathrm{mGy}$ ( $3 \mathrm{~min}$ anterior-posterior plus a 3-min left-right procedure), respectively. The maximal skin doses of the fluoroscopic system were equal to those of MIT and HIT. In single fraction treatment for lung cancer ${ }^{(26)}$, the beam is delivered to the target from four beam directions with vertical or horizontal beams in two oblique positions. The total effective dose for lung treatment was 1.9$3.2 \mathrm{mSv}(=0.48-0.79 \mathrm{mSv} /$ beam angle $\times 4$ beams $)$. The maximal skin dose for lung treatment was 23.6-
$39.6 \mathrm{mGy}(=5.9-9.9 \mathrm{mGy} /$ beam angle $\times 4$ beams $)$. Fujii et al. ${ }^{(18)}$ reported that effective dose of multidetector-row CT examination was $8.4-10.9 \mathrm{mSv}$ on chest examination. Mori et al. ${ }^{(11)}$ reported that effective doses from helical CT scan mode and from 4DCT scan mode were 6.09 and $24.7 \mathrm{mSv}$ in thoracic regions for treatment planning, respectively. Matsuzaki et $a .^{(12)}$ reported that effective dose of helical 4DCT was $33.1 \mathrm{mSv}$ in thoracic regions for treatment planning. For lung treatment, the total effective doses from fluoroscopy were lower than CT in thoracic regions for treatment planning. However the total effective dose from fluoroscopy depends on specific treatment protocol. Because the prescribed dose range in single fraction treatment from the fluoroscopy was from 36.0 to $46.0 \mathrm{GyE}^{(27)}$, the maximal skin dose for lung treatment was $\sim 1000$ times lower than the dose from the carbon-ion beam itself. Even if the planned dose is already very close to the tolerance dose, an additional dose from fluoroscopy would rarely trigger the deterministic effect.

The authors estimated the fluoroscopic imaging dose using an adult anthropomorphic phantom with a lung cancer treatment protocol. The optimised exposure dose for a markerless tracking system equals the minimal exposure dose which can track the anatomical structures, e.g. tumour and pulmonary blood vessels. The visibility of anatomic structures, e.g. tumour and pulmonary blood vessels, is a key factor in the accuracy of markerless tumour tracking in the thorax. The exposure condition was set not by an image quality index, namely image resolution and signal-to-noise ratio, but by the visibilities of the figure and outline of pulmonary blood vessels in the region around the isocentre in the images (Figure 3). The exposure condition for thoracic region was set based on fluoroscopic images of anthropomorphic phantom. On the other hand, that for abdominal region was not set by using anthropomorphic phantom because anatomical structures were not visible. Therefore, the tube voltage of X-ray beam for abdominal region was determined according to the condition for patient setup. The individual imaging dose is actually dependent on the treatment protocol (e.g. gating window and number of fractions) and patient characteristics (e.g. respiratory pattern and body type); nevertheless, these results are useful in estimating the imaging dose from exposure conditions.

\section{CONCLUSION}

The present results could show the radiation dose level in image-guided respiration-gated radiotherapy by estimating organ dose and effective dose. The fluoroscopic imaging dose was compared with therapeutic beam for a gated strategy in carbon-ion radiotherapy according to treatment protocol. These results would be helpful to optimise the imaging dose in image-guided radiotherapy. 


\section{REFERENCES}

1. Pedroni, E. et al. The PSI Gantry 2: a second generation proton scanning gantry. Z. Med. Phys. 14, 25-34 (2004).

2. Combs, S. E., Ellerbrock, M., Haberer, T., Habermehl, D., Hoess, A. and Jäkel, O. Heidelberg Ion Therapy Center (HIT): initial clinical experience in the first 80 patients. Acta. Oncol. 49, 1132-1140 (2010).

3. Mori, S., Shibayama, K., Tanimoto, K., Kumagai, M., Matsuzaki, Y. and Furukawa, T. First clinical experience in carbon ion scanning beam therapy: retrospective analysis of patient positional accuracy. J. Radiat. Res. 53, 760-768 (2012).

4. Korreman, S. S., Juhler-Nttrup, T. and Boyer, A. L. Respiratory gated beam delivery cannot facilitate margin reduction, unless combined with respiratory correlated image guidance. Radiother. Oncol. 86, 61-68 (2008).

5. Shirato, H. et al. Physical aspects of a real-time tumortracking system for gated radiotherapy. Int. J. Rad. Oncol. Biol. Phys. 48, 1187-1195 (2000).

6. Shirato, H., Oita, M., Fujita, K., Watanabe, Y. and Miyasaka, K. Feasibility of synchronization of real-time tumor-tracking radiotherapy and intensity-modulated radiotherapy from viewpoint of excessive dose from fluoroscopy. Int. J. Rad. Oncol. Biol. Phys 60, 335-341 (2004).

7. Cui, Y., Dy, J. G., Sharp, G. C., Alexander, B. and Jiang, S. B. Multiple template-based fluoroscopic tracking of lung tumor mass without implanted fiducial markers. Phys. Med. Biol. 52, 6229-6242 (2007).

8. Gendrin, C. et al. Monitoring tumor motion by real time $2 D / 3 D$ registration during radiotherapy. Radiother. Oncol. 102, 274-280 (2012).

9. Rietzel, E. and Bert, C. Respiratory motion management in particle therapy. Med. Phys. 37, 449-460 (2010).

10. Mori, S., Furukawa, T., Inaniwa, T., Zenklusen, S., Nakao, M., Shirai, T. and Noda, K. Systematic evaluation of four-dimensional hybrid depth scanning for carbon-ion lung therapy. Med. Phys. 40, 031720 (2013).

11. Mori, S., Ko, S., Ishii, T. and Nishizawa, K. Effective doses in four-dimensional computed tomography for lung radiotherapy planning. Med. Dosim. 34, 87-90 (2009).

12. Matsuzaki, Y., Fujii, K., Kumagai, M., Tsuruoka, I. and Mori, S. Effective and organ doses using helical 4DCT for thoracic and abdominal therapies. J. Radiat. Res. 54, 962-970 (2013).

13. Steiner, E. et al. Imaging dose assessment for IGRT in particle beam therapy. Radiother. Oncol. 109, 409-413 (2013).

14. Hubbell, J. H. and Seltzer, S. M. Tables of X-ray mass attenuation coefficients and mass energy-absorption coefficients from $1 \mathrm{keV}$ to $20 \mathrm{MeV}$ for elements $Z=1$ to 92 and 48 additional substances of dosimetric interest. NISTIR 5632. National Institute of Standards and Technology (1995).

15. International Commission on Radiological Protection. The 2007 recommendations of the International Commission on Radiological Protection. ICRP Publication 103. Elsevier, $\operatorname{ICRP}(2007)$.

16. Araki, F., Ikegami, T., Ishidoya, T. and Kubo, H. D. Measurements of gamma-knife helmet output factors using a radiophotoluminescent glass rod dosimeter and a diode detector. Med. Phys. 30, 1976-1981 (2003).

17. International Commission of Radiation Units and Measurements. Photon, electron, proton and neutron interaction data for body tissues. ICRU report 46, ICRU (1992).

18. Fujii, K., Aoyama, T., Koyama, S. and Kawaura, C. Comparative evaluation of organ and effective doses for paediatric patients with those for adults in chest and abdominal CT examinations. Br. J. Radiol. 80, 657-667 (2007).

19. International Commission on Radiological Protection. Basic anatomical and physiological data for use in radiological protection: the skeleton. ICRP Publication 70, Ann ICRP 25(2), Pergamon Press (1995).

20. International Commission on Radiological Protection. Age-dependent doses to members of the public from intake of radionuclides: Part 2. Ingestion dose coefficients. ICRP Publication 67, Ann ICRP 23(3-4). Pergamon Press (1996).

21. Seguchi, S., Aoyama, T., Koyama, S., Kawaura, C. and Fujii, K. Evaluation of exposure dose to patients undergoing catheter ablation procedures-a phantom study. Eur. Radiol. 18, 2559-2567 (2008).

22. Rasband, W. Image $\mathbf{J}$ (version v1.45 s). National Institute of Health (2011). Available on http://rsb.info.nih.gov/ij/.

23. Hsu, S. M., Yeh, S. H., Lin, M. S. and Chen, W. L. Comparison on characteristics of radiophotoluminescent glass dosemeters and thermoluminescent dosemeters. Radiat. Prot. Dosim. 119, 327-331, (2006).

24. Manninen, A. L., Koivula, A. and Nieminen, M. T. The applicability of radiophotoluminescence dosemeter ( $R P L D)$ for measuring medical radiation (MR) doses. Radiat. Prot. Dosim. 151, 1-9 (2012).

25. Furukawa, T., Inaniwa, T., Sato, S., Shirai, T., Mori, S., Takeshita, E., Mizushima, K., Himukai, T. and Noda, $\mathrm{K}$. Moving target irradiation with fast rescanning and gating in particle therapy. Med. Phys. 37, 4874-4879 (2010).

26. Yamamoto, N., Baba, M., Nakajima, M., Yoshikawa, K., Matsufuji, N., Minohara, S., Tsuji, H., Kamada, T. and Tsujii, H. Carbon ion radiotherapy in a hypofraction regimen for Stage I non-small cell lung cancer. In: Proceedings of NIRS-KFSHRC Joint Symposium on Carbon Ion Radiotherapy and Radiation Emergency Medicine. February 2012. NIRS-M-246, pp. 26-36 (2012).

27. Kanai, T., Matsufuji, N., Miyamoto, T., Mizoe, J., Kamada, T., Tsuji, H., Kato, H., Baba, M. and Tsujii, H. Examination of GyE system for HIMAC carbon therapy. Int. J. Rad. Oncol. Biol. Phys. 64, 650-656 (2006). 